\title{
Class II malocclusion occlusal severity description
}

\author{
Guilherme JANSON ${ }^{1}$, Renata SATHLER ${ }^{2}$, Thais Maria Freire FERNANDES ${ }^{2}$, Marcelo ZANDA $^{3}$, Arnaldo PINZAN ${ }^{4}$
}

1- DDS, MSc, PhD, MRCDC (Member of the Royal College of Dentists of Canada), Professor and Head, Department of Pediatric Dentistry, Orthodontics and
Community Health, Bauru School of Dentistry, University of São Paulo, Bauru, SP, Brazil.
2- DDS, Orthodontics Graduate Student, Department of Pediatric Dentistry, Orthodontics and Community Health, Bauru School of Dentistry, University of São
Paulo, Bauru, SP, Brazil.
3- DDS, MSc, PhD, Department of Stomatology, Bauru School of Dentistry, University of São Paulo, Bauru, SP, Brazil.
4- DDS, MSc, PhD, Associate Professor, Department of Pediatric Dentistry, Orthodontics and Community Health, Bauru School of Dentistry, University of São
Paulo, Bauru, SP, Brazil.

Corresponding address: Dr. Guilherme Janson - Faculdade de Odontologia de Bauru - USP - Departamento de Odontopediatria, Ortodontia e Saúde Coletiva Alameda Octávio Pinheiro Brisolla, 9-75 - Bauru - SP - 17012-901 - Phone/Fax: 551432344480 - e-mail: jansong@travelnet.com.br

Received: February 20, 2009 - Modification: October 02, 2009 - Accepted: December 15, 2009

\section{ABSTRACT}

\begin{abstract}
$\mathrm{O}$ bjectives: It is well known that the efficacy and the efficiency of a Class II malocclusion treatment are aspects closely related to the severity of the dental anteroposterior discrepancy. Even though, sample selection based on cephalometric variables without considering the severity of the occlusal anteroposterior discrepancy is still common in current papers. In some of them, when occlusal parameters are chosen, the severity is often neglected. The purpose of this study is to verify the importance given to the classification of Class II malocclusion, based on the criteria used for sample selection in a great number of papers published in the orthodontic journal with the highest impact factor. Material and Methods: A search was performed in PubMed database for full-text research papers referencing Class II malocclusion in the history of the American Journal of Orthodontics and Dentofacial Orthopedics (AJO-DO). Results: A total of 359 papers were retrieved, among which only $72(20.06 \%)$ papers described the occlusal severity of the Class II malocclusion sample. In the other 287 (79.94\%) papers that did not specify the anteroposterior discrepancy severity, description was considered to be crucial in 159 $(55.40 \%)$ of them. Conclusions: Omission in describing the occlusal severity demands a cautious interpretation of $44.29 \%$ of the papers retrieved in this study.
\end{abstract}

Key words: Malocclusion, angle class II. Severity.

\section{INTRODUCTION}

Communication among practitioners was dramatically simplified when Angle $^{7}$ (1899) first described the classification of malocclusion. By that time, he proposed only 3 categories in which malocclusions should be fitted in. Years after that, Andrews ${ }^{4}$ (1972) understood the necessity of a more complete classification as he proposed the six keys to normal occlusion and described a more precise classification of the anteroposterior occlusal discrepancy ${ }^{5,6}$ (Figure 1). This upgrade in the description of malocclusion not only facilitated comprehension of the problem but also gave Orthodontics a more scientific aspect. Currently, classification of Class II malocclusion is primarily based on these authors. Despite their effort to improve it, there is still a need for more details when describing the anteroposterior discrepancy ${ }^{1,31}$.
Recognition of occlusal malocclusion severity is important to determine the best treatment approach. The same malocclusion although with differing severity will be amenable to very different treatment protocols $11,20,23,28$. A full cusp Class II malocclusion, for example, requires more patient compliance in using removable orthodontic devices and more ability and experience of the orthodontist, than a $1 / 4$ cusp Class II malocclusion ${ }^{22}$. However, it is very unusual to find papers that clearly provide the occlusal discrepancy severity of the sample used. Additionally, the use of cephalometric variables is often more common than the occlusal parameters, although suggestion of including additional occlusal details has been made ${ }^{24,38}$.

Concerns about these omissions and the quality of the published studies is not a recent issue $e^{24,30,36-38}$. Research design, sample size and selection are the major source of bias in all studies assessed ${ }^{38}$. 


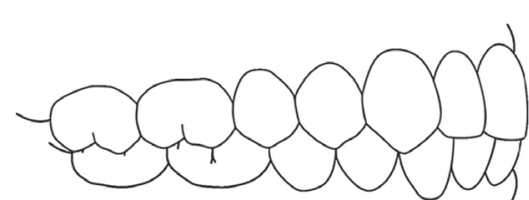

Class I

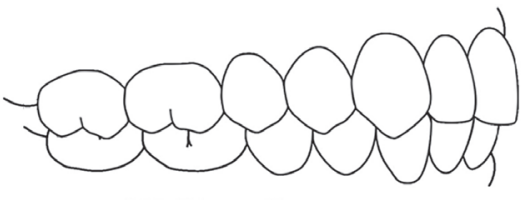

1/4 Class II

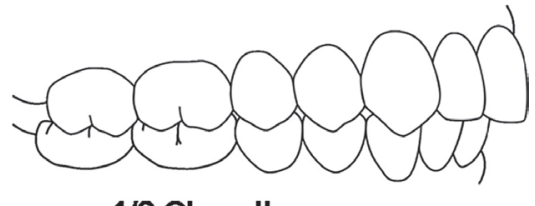

$1 / 2$ Class II

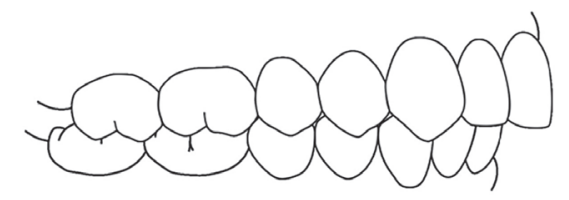

3/4 Class II

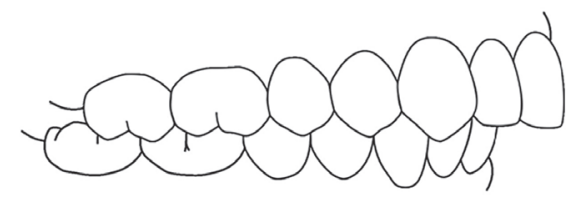

Full Class II

Figure 1- Illustration of a Class I anteroposterior relationship and increasing Class II malocclusion anteroposterior occlusal severities

Therefore, the purposes of this study were to identify the importance given to the description of Class II malocclusion occlusal severity and to discuss its implications.

\section{MATERIAL AND METHODS}

In January 2008 a search was performed in PubMed database (Figure 2). The objective was to find research papers dealing with Class II malocclusion samples. Case reports were not included. For a more uniform search, only one journal was considered, the American Journal of Orthodontics and Dentofacial Orthopedics. This would minimize the odds of combining papers with different selection standards. There was no date limit for the search and every one of the 359 retrieved papers was analyzed.

The Material and Methods section of each paper was thoroughly read, and the criterion used for sample inclusion or exclusion was recorded. This sample selection criterion was considered only if it was placed under the Material and Methods section. When there was no Material and Methods section available, the whole paper was read. The goal was to understand the importance given to the malocclusion severity description.

The papers were divided based on the malocclusion report. The parameters used to describe the sample varied greatly. Some described malocclusion severity of the sample in a clear, precise way. Others used only occlusal features or only cephalometric variables or even both to describe the sample, but without specifying the occlusal severity. And yet, there were even those that did not mention any sort of severity parameter.

Use of the term "Angle Class II malocclusion" or similar, was considered as occlusal parameter, following the root of Angle's classification. In cases that the criteria for sample selection were unclear, common sense was used to classify the paper in the most precise parameter possible.

Based on these data, the papers were ultimately divided as: "With Occlusal Severity Specification" and "Without Occlusal Severity Specification" (Table 1 ). The following terms were accepted as severity descriptors: mild, moderate, severe; complete, full unit, full cusp, cusp-to-cusp, half cusp, half cusp unit; edge-to-edge, end-to-end, end-on and the use of quarters or millimeters.

To be included in the "With Occlusal Severity Specification" category, the criteria had to be occlusal severity only, in a clear way, regardless of any other occlusal or cephalometric parameter. Therefore, the few papers that used primarily other parameters for sample selection, such as overjet or the ANB angle and secondarily also mentioned occlusal severity, were placed in other category.

When all papers were classified, their objectives were analyzed to verify if there was, indeed, a need for occlusal severity specification. The abstracts of those that did not specify the occlusal severity level were analyzed and separated according to the need of occlusal severity description based on the aim of the paper (Tables 2 and 3). In those papers concerning comparative studies, orthodontic device effects, treatment, protocol or technique effects, or investigation of Class II malocclusion

\section{PubMed}

(("Malocclusion, Angle Class II"[Mesh] AND (hasabstract[text]) NOT ("Case Reports"[Publication Type])) AND ("American journal of orthodontics and dentofacial orthopedics : official publication of the American Association of Orthodontists, its constituent societies, and the American Board of Orthodontics"[Jour]))

Figure 2- Database and method of search 
Table 1- Prevalence of Class II malocclusion occlusal severity specification

\begin{tabular}{ccc}
\hline With/Without & $\begin{array}{c}\text { Occlusal Severity Specification } \\
\text { Number of papers }\end{array}$ & Percentage \\
\hline & & \\
With & 72 & $20.06 \%$ \\
Without & 287 & $79.94 \%$ \\
\hline
\end{tabular}

Table 2- Need for occlusal severity specification

\begin{tabular}{cc}
\hline \multicolumn{2}{c}{ Papers Without Occlusal Severity Specification } \\
Considered necessary & Not considered necessary \\
\hline $159(55.40 \%)$ & $128(44.60 \%)$ \\
\hline
\end{tabular}

Table 3- Overall need for occlusal severity specification

\begin{tabular}{|c|c|c|}
\hline With & Without & Without \\
\hline Severity Specification & Severity Specification* & Severity Specification** \\
\hline $72(20.06 \%)$ & $128(35.65 \%)$ & $159(44.29 \%)$ \\
\hline
\end{tabular}

* Occlusal severity specification was not considered crucial

** Occlusal severity specification was considered crucial

Table 4- Evolution of occlusal severity specification throughout time

\begin{tabular}{ccc}
\hline Group & With Specification & Without Specification \\
\hline & & \\
Group 1 (1986-1992) & $7(10.14 \%)$ & $62(89.86 \%)$ \\
Group 2 (1993-1997) & $16(21.05 \%)$ & $60(78.95 \%)$ \\
Group 3(1998-2002) & $15(15.00 \%)$ & $85(85.00 \%)$ \\
Group 4 (2003-2007) & $34(29.82 \%)$ & $80(70.18 \%)$ \\
\hline
\end{tabular}

Table 5- Need for occlusal severity specification throughout time

\begin{tabular}{ccc}
\hline \multicolumn{3}{c}{ Without Specification } \\
\hline Group & Necessary & Not necessary \\
\hline Group 1 (1986-1992) & $24(38.71 \%)$ & $38(61.29 \%)$ \\
Group 2(1993-1997) & $39(65.00 \%)$ & $21(35.00 \%)$ \\
Group 3 (1998-2002) & $45(52.94 \%)$ & $40(47.06 \%)$ \\
Group 4 (2003-2007) & $51(63.75 \%)$ & $29(36.25 \%)$ \\
\hline
\end{tabular}

characteristics, occlusal severity specification was considered mandatory. In reviews and researches, severity was not considered relevant. Papers that used different samples, such as Class I, were eliminated. Those were probably retrieved in the search because of the terms used by the authors as descriptors.

To understand the evolution of sample description, the papers were divided into four time intervals to easily demonstrate how much importance occlusal severity report has gained in the last years (Tables 4 and 5).

\section{RESULTS}

Among the 359 retrieved papers, 72 (20.06\%) quoted the occlusal anteroposterior discrepancy severity amount and used it as a single parameter for sample selection (Table 1 ). The other 287 (79.94\%) papers did not specify the occlusal malocclusion severity or, if so, it was only considered if other occlusal and cephalometric parameters had been satisfied. In the papers that did not specify the anteroposterior discrepancy severity, description was considered to be crucial in 159 (55.40\%) (Table 2 ). Considering the total sample of 359 papers, severity description should have been mentioned in $44.29 \%$ of them (Table 3 ).

Concern in describing occlusal anteroposterior discrepancy severity increased in the latest years (Table 4). Between 2003 and 2007, occlusal severity specification represented $29.82 \%$ of the sample while between 1986 and 1992 it was of only $10.14 \%$ (Table 4). Conversely, omission of severity description in those papers where it was considered to be essential increased lately (Table 5). Between 1986 and 1992 , this omission was of $38.71 \%$, and 
increased to $63.75 \%$ between 2003 and 2007 .

\section{DISCUSSION}

There is a restless need for more clear, fair and accurate papers so conclusions can be extrapolated to the clinical practice. To identify if some basic elements methodically took part in the literature, a search was performed to check whether Class II malocclusion occlusal severity was appropriately described in the papers, when necessary. To work with a reasonable amount of representative high standard orthodontic papers, this search retrieved only those published in the AJO-DO because, according to the 2007 ISI Journal Citation Reports, this journal is the highest ranked orthodontic title, by number of citations and impact factor.

\section{Prevalence of Occlusal Severity Specification}

Angle $^{7}$ (1899) and Andrews $^{4}$ (1972) used occlusal rather than cephalometric parameters to describe malocclusion of the teeth. Despite that, some of the latest orthodontic papers still classify malocclusion based only on cephalometric variables instead of using occlusal parameters. In some of them, part of the sample was rejected because it presented "dental but not skeletal Class II malocclusion"32,34.

Among the 359 papers retrieved in this search, only $72(20 \%)$ specified the occlusal severity of the sample, regardless of any other occlusal or cephalometric parameter (Table 1). This demonstrates the little importance given to dental relationships, which are the most important characteristics to be corrected in the great majority of orthodontic cases $^{27}$. This probably happened because after development of cephalometrics there was an emphasis on the cephalometric characteristics of the malocclusion, placing dental relationships on a secondary level ${ }^{15}$. Along with the cephalometric characteristics, emphasis was given on the skeletal components of malocclusion and this has been the tendency throughout time ${ }^{13,29}$. However, it is usually not the skeletal characteristics of a Class II malocclusion that primarily determine how it should be treated but, rather, the dentoalveolar characteristics ${ }^{19}$. In addition, it has also been shown that the cephalometric variables will influence the esthetic prognosis but not the treatment occlusal success rate ${ }^{21}$.

Some papers have selected skeletal Class II malocclusion subjects based exclusively on cephalometric parameters ${ }^{15,18}$. There is a great deficiency in this procedure because patients can present a normal occlusion despite great basal bone cephalometric anteroposterior discrepancy ${ }^{42}$. Therefore, whenever the effects of a certain appliance in the correction of Class II malocclusion are evaluated, it is crucial that the occlusal anteroposterior discrepancy should be clearly measured. This procedure not only clarifies the sample characteristics but also best describes the treatment difficulty of the case.

Overjet was also frequently used as description for anteroposterior discrepancy. Sometimes it was used as the only parameter as if it was only present in Class II malocclusions. Overjet is very influenced by labial inclination of anterior teeth. The presence of diastemas can also significantly increase it and it is very possible to have a Class I malocclusion with increased overjet. In these cases, the maxillary incisors may be severely labially tipped associated or not with diastemas and the mandibular anterior teeth may be crowded $3,12,26$. This does not require great mechanical effort to correct the anteroposterior discrepancy because the posterior teeth are in a Class I relationship ${ }^{42}$. Therefore, this parameter is by no means enough to describe Class II malocclusion severity.

Deficiency in severity description was evident in some papers were malocclusion was described as "borderline subjects" 9 or "Class II incisal relationship"16,35 or "most Class II subjects" 40 or "there was a preponderance of Class II malocclusions" 33 or "all Class II patients" 28 or "the profile had a Class II appearance"8 or "...this study was not treatment of any Class II malocclusion; it was a study of the orthodontic treatment of difficult Class II malocclusions..." ${ }^{17}$ (Italics from the author). These descriptors are very indistinct and do not allow a precise estimation of the amount of Class II anteroposterior discrepancy.

It was also observed that usually the experimental groups followed rigid occlusal anteroposterior discrepancy criteria while the control groups did not ${ }^{25}$. Therefore, results of these comparisons could be compromised. Omission in describing Class II malocclusion severity could explain why there are sometimes contrasting results. While some authors report significant effects, others fail in demonstrating them. Therefore, basic questions remain unanswered ${ }^{38}$.

\section{Studies that Demanded Occlusal Severity Specification}

Papers that did not specify the severity level were analyzed whether occlusal severity specification was mandatory based on the aim of the study. Among those classified as "Without Occlusal Severity Specification", in 159 papers (55.40\%) severity specification was judged to be crucial. This means that the results and conclusions of these works could be compromised by the unspecific anteroposterior severity description. As it is known, comparative studies and Class II investigations need matched samples to avoid bias. Furthermore, if a device or technique is being tested in a sample with mild 
severity, results naturally tend to praise the system being tested without considering the simplicity to correct the Class II malocclusion (Tables 2 and 3).

\section{Occlusal Severity Specification over the Years}

The results demonstrated that occlusal severity description has gained some attention through the years. Specification increased three times from 1986 to 2007. It seems that concerns in specifying Class II malocclusion severity reflects the improvement in malocclusion classification developed by Andrews, with his paper "The six keys to normal occlusion", in $1972^{4}$. His textbook also illustrates how cases from the American Board progressively improved at the end of treatment in the 1960's, 1970's and 1980 's $\mathrm{s}^{6}$. This improvement is certainly due to the consideration and attention on the final occlusal aspects of the cases to be judged, since the mission of the American Board of Orthodontics is to establish and maintain the highest standards of clinical excellence by evaluating clinical competence ${ }^{39}$. As concerns with detailed finishing increased, investigators and clinicians realized that greater specification of malocclusion severity, especially Class II malocclusion anteroposterior discrepancy, was necessary to satisfactorily describe treatment difficulty. However, although there have been an increasing number of papers describing Class II malocclusion occlusal severity (Table 4), the percentage of papers without specification in which it was mandatory increased (Table 5). This shows that the importance of malocclusion occlusal severity has been underestimated.

It must been understood that Class II malocclusion occlusal severity specification is correlated to treatment plan and time, and to the mechanical difficulty in handling the malocclusion, and therefore it has to be precisely described $2,10,14,21,22,41$. Class II malocclusion occlusal severity features should be more thoroughly described in scientific papers to provide a better understanding of treatment difficulties of this malocclusion.

\section{CONCLUSIONS}

Class II malocclusion occlusal severity description is a very important characteristic and has to be specified in the great majority of Orthodontic papers. This parameter is well-known and very simple to understand and to use as a classification. Despite the importance and the simplicity of occlusal severity specification, it has not been systematically used. Consequently, the results of some papers should be cautiously interpreted.

\section{REFERENCES}

1- Ackerman JL, Proffit WR. The characteristics of malocclusion: a modern approach to classification and diagnosis. Am J Orthod. 1969;56(5):443-54. 2-Alavi DG, BeGole EA, Schneider BJ. Facial and dental arch asymmetries in Class II subdivision malocclusion. Am J Orthod Dentofacial Orthop. 1988;93(1):38-46.

3-Alexander CD. Open bite, dental alveolar protrusion, class I malocclusion: a successful treatment result. Am J Orthod Dentofacial Orthop. 1999;116(5):494-500.

4- Andrews LF. The six keys to normal occlusion. Am J Orthod. 1972;62(3):296-309.

5- Andrews LF. The straight wire appliance. Syllabus of philosophy and techniques. San Diego: Larry F. Andrews Foundation of Orthodontic Education and Research; 1975. p. 109-41.

6- Andrews LF. Straight-wire, the concept and the appliance. San Diego: L. A. Well; 1989

7- Angle EH. Classification of malocclusion. Dent Cosmos. 1899;41:24864,350-7.

8- Baik CY, Ververidou M. A new approach of assessing sagittal discrepancies: the Beta angle. Am J Orthod Dentofacial Orthop. 2004;126(1):100-5

9- Beattie JR, Paquette DE, Johnston LE Jr. The functional impact of extraction and nonextraction treatments: a long-term comparison in patients with "borderline," equally susceptible Class II malocclusions. Am J Orthod Dentofacial Orthop. 1994;105(5):444-9.

10- Bishara SE. Mandibular changes in persons with untreated and treated Class II division 1 malocclusion. Am J Orthod Dentofacial Orthop. 1998;113(6):661-73.

11- Bishara SE, Cummins DM, Zaher AR. Treatment and posttreatment changes in patients with Class II, Division 1 malocclusion after extraction and nonextraction treatment. Am J Orthod Dentofacial Orthop. 1997;111(1):1827.

12- Cuebas JO. Nonsurgical treatment of a skeletal vertical discrepancy with a significant open bite. Am J Orthod Dentofacial Orthop. 1997;112(2):124-31. 13- Cura N, Sarac M, Ozturk Y, Surmeli N. Orthodontic and orthopedic effects of Activator, Activator-HG combination, and Bass appliances: a comparative study. Am J Orthod Dentofacial Orthop. 1996;110(1):36-45.

14- Dolce C, Schader RE, McGorray SP, Wheeler TT. Centrographic analysis of 1-phase versus 2-phase treatment for Class II malocclusion. Am J Orthod Dentofacial Orthop. 2005;128(2):195-200.

15- Ghafari J, Jacobsson-Hunt U, Markowitz DL, Shofer FS, Laster LL. Changes of arch width in the early treatment of Class II, division 1 malocclusions. Am J Orthod Dentofacial Orthop. 1994;106(5):496-502.

16- Gill DS, Lee RT. Prospective clinical trial comparing the effects of conventional Twin-block and mini-block appliances: Part 1. Hard tissue changes. Am J Orthod Dentofacial Orthop. 2005;127(4):465-72; quiz 517. 17- Gramling JF. The Probability Index. Am J Orthod Dentofacial Orthop. 1995;107(2):165-71.

18- Hoffelder LB, de Lima EM, Martinelli FL, Bolognese AM. Soft-tissue changes during facial growth in skeletal Class II individuals. Am J Orthod Dentofacial Orthop. 2007;131(4):490-5.

19- Janson G, Brambilla Ada C, Henriques JF, Freitas MR, Neves LS. Class II treatment success rate in 2- and 4-premolar extraction protocols. Am J Orthod Dentofacial Orthop. 2004;125(4):472-9.

20- Janson G, Graciano JT, Henriques JF, Freitas MR, Pinzan A, PinzanVercelino CR. Occlusal and cephalometric Class II Division 1 malocclusion severity in patients treated with and without extraction of 2 maxillary premolars. Am J Orthod Dentofacial Orthop. 2006;129(6):759-67.

21- Janson G, Janson M, Nakamura A, Freitas MR, Henriques JF, Pinzan A. Influence of cephalometric characteristics on the occlusal success rate of Class II malocclusions treated with 2- and 4-premolar extraction protocols. Am J Orthod Dentofacial Orthop. 2008;133(6):861-8.

22- Janson G, Valarelli FP, Cançado RH, Freitas MR, Pinzan A. Relationship between malocclusion severity and treatment success rate in Class II nonextraction therapy. Am J Orthod Dentofacial Orthop. 2009;135(3):274 e1-8; discussion 274-5. 
23- Janson M, Janson G, Sant'Ana E, Simão TM, Freitas MR. An orthodonticsurgical approach to Class II subdivision malocclusion treatment. J App Oral Sci. 2009;17(3):266-73.

24- Keeling SD, McGorray S, Wheeler TT, King GJ. Imprecision in orthodontic diagnosis: reliability of clinical measures of malocclusion. Angle Orthod. 1996;66(5):381-91.

25- LaHaye MB, Buschang PH, Alexander RG, Boley JC. Orthodontic treatment changes of chin position in Class II Division 1 patients. Am J Orthod Dentofacial Orthop. 2006;130(6):732-41.

26- Martina R, Laino A, Michelotti A. Class I malocclusion with severe open bite skeletal pattern treatment. Am J Orthod Dentofacial Orthop. 1990;97(5):363-73.

27- Ormiston JP, Huang GJ, Little RM, Decker JD, Seuk GD. Retrospective analysis of long-term stable and unstable orthodontic treatment outcomes. Am J Orthod Dentofacial Orthop. 2005;128(5):568-74; quiz 669.

28- Paquette DE, Beattie JR, Johnston LE Jr. A long-term comparison of nonextraction and premolar extraction edgewise therapy in "borderline" Class II patients. Am J Orthod Dentofacial Orthop. 1992;102(1):1-14.

29- Pollard LE, Mamandras AH. Male postpubertal facial growth in Class II malocclusions. Am J Orthod Dentofacial Orthop. 1995;108(1):62-8.

30- Proffit WR. The evolution of orthodontics to a data-based specialty. Am J Orthod Dentofacial Orthop. 2000;117(5):545-7.

31- Proffit WR, Ackerman JL. Rating the characteristics of malocclusion: a systematic approach for planning treatment. Am J Orthod. 1973;64(3):25869.

32- Proffit WR, Phillips C, Douvartzidis N. A comparison of outcomes of orthodontic and surgical-orthodontic treatment of Class II malocclusion in adults. Am J Orthod Dentofacial Orthop. 1992;101(6):556-65.
33- Sadowsky C, Schneider BJ, BeGole EA, Tahir E. Long-term stability after orthodontic treatment: nonextraction with prolonged retention. Am J Orthod Dentofacial Orthop. 1994;106(3):243-9.

34- Sarver DM. Soft-tissue-based diagnosis \& treatment planning. Clinical Impressions. 2005;14(1):21-6.

35- Sharma AA, Lee RT. Prospective clinical trial comparing the effects of conventional Twin-block and mini-block appliances: Part 2. Soft tissue changes. Am J Orthod Dentofacial Orthop. 2005;127(4):473-82.

36- Tulloch JF. Bias and variability in clinical research. Clin Orthod Res. 1998;1(2):94-6.

37- Tulloch JF, Antczak-Bouckoms AA, Tuncay OC. A review of clinical research in orthodontics. Am J Orthod Dentofacial Orthop. 1989;95(6):499504.

38- Tulloch JF, Medland W, Tuncay OC. Methods used to evaluate growth modification in Class II malocclusion. Am J Orthod Dentofacial Orthop. 1990;98(4):340-7.

39- Vaden JL, Kokich VG. American Board of Orthodontics: past, present, and future. Am J Orthod Dentofacial Orthop. 2000;117(5):530-2.

40- VanLaecken R, Martin CA, Dischinger T, Razmus T, Ngan P. Treatment effects of the edgewise Herbst appliance: a cephalometric and tomographic investigation. Am J Orthod Dentofacial Orthop. 2006;130(5):582-93.

41- Wheeler TT, McGorray SP, Dolce C, Taylor MG, King GJ. Effectiveness of early treatment of Class II malocclusion. Am J Orthod Dentofacial Orthop. 2002;121(1):9-17.

42- Zupancic S, Pohar M, Farcnik F, Ovsenik M. Overjet as a predictor of sagittal skeletal relationships. Eur J Orthod. 2008;30(3):269-73. 